

http://www.diva-portal.org

This is the published version of a paper published in Sport, Education and Society.

Citation for the original published paper (version of record):

Larsson, H., Karlefors, I. (2015)

Physical education cultures in Sweden: fitness, sports, dancing ... learning?.

Sport, Education and Society

http://dx.doi.org/10.1080/13573322.2014.979143

Access to the published version may require subscription.

N.B. When citing this work, cite the original published paper.

Permanent link to this version:

http://urn.kb.se/resolve?urn=urn:nbn:se:gih:diva-3725 


\title{
Physical education cultures in Sweden: fitness, sports, dancing ... learning?
}

\author{
Håkan Larsson ${ }^{\mathrm{a} \star}$ and Inger Karlefors ${ }^{\mathrm{b}}$ \\ ${ }^{\mathrm{a}}$ The Swedish School of Sport and Health Sciences, Stockholm, Sweden; ${ }^{\mathrm{b}}$ Department of \\ Education, Umeå University, Umeå, Sweden
}

In a significant article from 1993, Crum describes the purpose of physical education (PE) as a 'planned introduction into movement culture'. In broad terms, this purpose is tantamount to the stated purpose of Swedish PE in national steering documents. Crum contends, however, that physical educators do not prioritise learning, which is largely due to the different 'movement cultures' that constitute the PE lessons. This article explores how practice unfolds in movement cultures that are included in Swedish PE and their implications for teaching and learning in the subject. Some 30 (indoor) PE lessons in eight secondary schools in four cities throughout Sweden were video recorded. At 'first glance' these lessons indicated the prevalence of four logics of practice: a physical training logic, a sports logic, a sport technique logic and a dance logic. However, further analysis revealed that the teachers' and students' actions were not entirely in line with a logic of practice of training the body, winning the game, learning sporting skills or learning to dance. Instead, the PE practice largely unfolded as a 'looks-like-practice', where the purpose of teaching was blurred, and where any 'planned introduction into movement culture' was difficult to identify. In the final section, the authors discuss how physical activity logics can be recontextualised in a PE setting in order to emphasise the educational contribution of PE.

Keywords: Physical education; Movement cultures; Teaching and learning; Fitness; sports; Dancing

\section{Introduction}

In the last few decades 'knowledge and learning' have become leitmotifs in discussions about physical education (PE; Nyberg \& Larsson, 2014). In autumn 2011 we observed a number of PE lessons in secondary schools throughout Sweden with the overall aim of exploring what constitutes important knowledge in PE and the processes of teaching and learning that take place in the subject. During our visits to the schools we observed that the lessons, at least superficially, appeared to be about improving fitness, learning sporting techniques, competing in sports or learning to dance. However, on scrutinising the lessons further we began to realise that what we saw at first glance was, at least in part, something different. Important from the point of view of our project, it struck us that it was difficult to judge 'from the sidelines' what was considered to be important knowledge and what the students were actually supposed to learn from the different activities, especially as it was not entirely clear that they were

^Corresponding author. The Swedish School of Sport and Health Sciences, Stockholm, Sweden. Email: hakan.larsson@gih.se 
supposed to develop their fitness or sporting and dancing skills. Overall, we remained puzzled about what kind of knowledge was considered to be important, what the students were supposed to learn and what the teachers were supposed to teach.

Our attempts to relate these preliminary observations to the literature took us back to the 1993 article about movement cultures in PE by Bart Crum. Movement cultures are ways 'in which a social group deals with the need and desire for movement beyond labor or maintaining life' (Crum, 1993). Historically, many of these cultures were not shaped for educational purposes, but as they are also used in schools, they affect how and what teachers teach (or do not teach), and what students learn (or do not learn). In fact, Crum argues that PE is imbued with a culture where 'the community of physical educators, in its professional values, does not unanimously accept and give priority to the proposition that a physical educator's primary function is to help pupils learn' (1993, p. 344). Drawing on Crum's insights, the purpose of this article is to further explore the ways in which practice unfolds in movement cultures that are included in Swedish PE, and how students and teachers, through their actions, negotiate what a PE lesson is about. Based on our findings, we discuss how different movement cultures can contribute educationally to PE, and how the subject's educational contribution can be reinforced.

\section{PE_-a subject undergoing change}

In 2011 the Swedish school curriculum was reformed with the intention of clarifying the educational contribution of every school subject. For the first time, so-called 'knowledge requirements', i.e. what students are supposed to know when they leave school, were included in the steering documents. The knowledge requirements for the part of PE in which students, for example, are expected to display how they 'with good quality of movement (can) perform a range of activities that improve physical ability' (SNAE, 2011b, p. 3) seem to some extent to be obscure to PE teachers. According to evaluations and inspections of the subject, a focus on knowledge and learning is difficult for teachers to implement pedagogically, especially in relation to a traditional content in the form of sports, keep-fit and outdoor activities (Quennerstedt, Öhman, \& Eriksson, 2008; SSI, 2010, 2012). In fact, already in 1991 Annerstedt claimed PE to be in a 'phase of uncertainty' regarding the educational contribution of the subject.

Internationally, there is not only talk about 'uncertainty', but also of a 'crisis' (McElroy, 2002; Stothart, 2005; Tinning \& Fitzclarence, 1992). This crisis is either framed in relation to external 'threats', such as the downsizing of resources and reduced time allocation (Marshall \& Hardman, 2000), or in relation to the inability of PE to live up to its own expectations (Bailey et al., 2009). According to Kirk (2010), the subject is trapped in a tendency for teachers to offer students a range of exercises that are supposed to develop their technical abilities to practise different sports. This is doomed to failure because: (1) the exercises are decontextualised, (2) too little time is devoted to a particular content and (3) teachers' competences in all the different sports are too shallow. Kirk argues that in order to avoid extinction, the subject needs to be radically reformed (Kirk, 2010). 
Although the situation in Sweden resembles Kirk's account, there are also differences. For example, the extent to which PE teachers try to teach sports techniques to their students is far less evident in Sweden, even though the impact of different sports is obvious (Liljekvist, 2013; Londos, 2010; Schenker, 2011). PE teachers in Sweden may find it difficult to clarify why PE is a mandatory school subject, although the idea that PE is 'something other' in relation to sport is indeed prominent (Annerstedt, 1991; see also Lundvall \& Meckbach, 2004). In our view, the situation in Sweden is similar to that described by Crum (1993), who argues that $\mathrm{PE}$ is characterised by a lack of time devoted to task, an overuse of direct teaching and inappropriate feedback or accountability (p. 344).

Since 2011, the overarching goal for elementary school PE (years 1-10) in Sweden is the development of students' 'all-round movement capacity and an interest in being physically active and spending time outdoors in nature'. Further, students should have 'the opportunity to develop knowledge in planning, applying and evaluating different types of activities involving physical movement' (SNAE, 2011a, p. 50). We believe this resonates well with Crum's assertion that the aim of PE should be a 'planned introduction into movement culture', where schools foster 'competencies for lasting participation in movement culture' (Crum, 1993, p. 342). Our interest here lies in how such learning objectives relate to the practice of PE in Swedish schools.

\section{Movement cultures in PE}

Ward (2014) contends that the movement cultures perspective offers a useful conceptual vantage point from which to seek to strengthen the integration of sport and PE. According to Crum (1993):

(m)ovement culture contains the set of movement actions and interactions (sport, play, dance, or other fitness activities) that encompass a group's leisure. [...] Movement culture emphasizes that exercise, play and sport are more than just physical activities and that these activities are governed by rules and are changeable. (p. 341)

However, Crum does not discuss the theoretical foundations of the concept movement cultures in any depth. Crum's way of depicting movement cultures resembles the way in which Engström (2008), inspired by Bourdieu (1990), describes different logics of practice within the field of sport and physical activity. While we take the concept 'movement culture' to be a comprehensive description of broader phenomena within society, we see 'logic of practice' as a more specific analytical tool to be used in research.

When physical activities are analysed in research, a common approach of researchers is to understand what people do from the point of view of what motivates individuals to do what they do, or what function the activity has in relation to educational or health benefits and sporting performance. However, analytically this is a way of reducing practice to mechanical behaviour governed by rational reasoning. 
Bourdieu offers another approach, where the analytical starting point is practice itself (1990). Bourdieu holds that practice should be understood on its own practical terms. But what does this mean? Practice is what people do in a particular social setting according to a set of historically and socially constituted, and mainly implicit, rules through which the actions/practice make sense. Practice 'unfolds in time and has all the correlative properties, [...]. Its temporal structure, that is, its rhythm, its tempo, and above all its directionality, is constitutive of its meaning' (p. 81). Interestingly, Bourdieu uses a sports metaphor to develop the significance of the relationship between directionality and temporality:

A player who is involved and caught up in the game adjusts not to what he sees but to what he fore-sees, sees in advance in the directly perceived present; he passes the ball not to the spot where his team-mate is but to the spot he will reach-before his opponent-a moment later [...] (p. 81)

Characteristic of the logic of practice is that an actor dwells in his or her practice, and does not decide what to do next from the point of view of a rational logic. Instead, the actor decides what to do from the point of view of the historically and socially constituted practicalities that govern what there is to fore-see in a practice in a way that he or she fulfils the logic of practice. However, the logic of practice is not a natural law. It is always possible to 'do something else', i.e. to change the logic even though the conditions that constitute different possible actions vary. Changing the logic of competitive sport during a FIFA World Cup final in football might be difficult and perhaps even improbable due to the amount of time and energy that the participants and others have invested in the cup matches leading up to the final. In contrast, a game of football during a PE lesson is quite another thing.

Based on this way of reasoning, Engström (2008) identifies a number of logics within the broader field of physical activity, which are to be seen as ideal types in a Weberian sense, and which mirror the movement cultures explicitly mentioned by Crum. These are:

- a sport logic, where competition, i.e. to 'beat the opponent' or 'win the game', constitutes the logic of practice;

- a sport-technique logic, where the learning of skills that are related to different sports constitutes the logic of practice;

- a keep-fit logic, where physical training, i.e. the endeavour to rationally train the body (strength, endurance, mobility, etc.) constitutes the logic of practice; and finally

- a dance logic, where aesthetic activities, i.e. movements following the rhythm of music in an attempt to express aesthetic values, constitutes the logic of practice.

Importantly, sport, keep-fit and dance practices have evolved historically in ways that underline, or support, the logic of practice. For instance, games, as an example of sports practices, cannot be played unless the teams attempt, at least to some extent, to score while at the same time protecting their own territory. 
There are other physical activity logics in society and potentially in PE but, as will be shown later, those mentioned above seemed, at first glance, to be prevalent in the Swedish PE lessons we visited. How do these logics of practice play out in a PE setting? Below, we return to how we have used the concept logic of practice in our analysis of movement cultures in PE lessons.

\section{Method}

The research project 'Physical education and health - a subject for learning?' started as a group of researchers from Stockholm, Gothenburg, Umeå and Örebro coming together in an endeavour to explore knowledge, teaching and learning in PE. Eight classes in eight different schools located in four Swedish cities (one lower secondary and one upper secondary class in each city) were followed for four PE lessons over one term. The schools and the classes were strategically selected in an effort to include schools from city centres, suburbs and rural areas, male and female teachers, and students taking vocational and academic courses. A total of 30 lessons, lasting between 40 and 80 minutes, were video recorded using two cameras; one stationary camera placed in a corner or on the gallery in order to (optimally) cover the collective actions in the gym, and one hand-held camera which was used to cover specific actions and interactions (e.g. talk) going on in the gym. For a further description of the study design and ethical considerations, see Quennerstedt et al. (2014).

The design of the study primarily served the purpose of making thick descriptions of teaching and learning processes in the gym (see e.g. Barker, Quennerstedt, \& Annerstedt, 2013, 2015; Redelius, Quennerstedt, \& Öhman, 2015). However, the width and depth of the material from the 30 lessons, about 50 hours of video footage, also allowed us to gain insights into PE movement culture; although our aim here is not to make any claims about which movement cultures dominate Swedish PE in general. The focus is on scrutinising how certain logics of practice in different movement cultures are either pursued or changed during PE lessons.

As indicated at the beginning of the article, our more or less spontaneous impression when visiting the gyms could be related to four of the logics of practice described by Engström (2008): a sport logic (competition), a sport-technique logic (learning skills), a keep-fit logic (physical training) and a dance logic (aesthetic activity). The logic of practice is expressed through how actions are temporally sequenced, their pace and intensity, and what the practitioners pay attention to, i.e. what they talk about and what they try to achieve-what end they fore-see. Hence, when reviewing the video-recorded lessons, we documented:

- how a particular lesson is structured (what happens first, and what happens next, the pace of the actions, how certain actions promote or, perhaps, hamper subsequent actions);

- what is communicated verbally about the purpose of the activities and how the stated purpose of the activity matches the logic of practice; 
- what the teacher and the students direct their attention towards when acting in and communicating about an activity; for what end they act.

Based on these items, when reviewing the video footage we paid particular attention to how the teachers and students attempted to pursue the logic that we saw at first glance, or the ways in which this logic was changed to steer the teachers' and students' actions in other directions than those one would expect. This approach is partly inspired by Ward and Quennerstedt's (2014) insights into the 'looks-like' culture of PE. In their analyses of UK primary school PE, what at first hand looked like real sports turned out to be a smorgasbord of looks-like-sports, where the real sports were diluted by a requirement for students' disciplined cooperation.

Due to limited space, and in an ambition to avoid drowning in individual events or lessons, what follows is a snapshot of some of the overarching patterns concerning the structure of the lessons, what is communicated verbally about the purpose, and what the teachers and students direct their attention towards when acting in and communicating about an activity, i.e. what they fore-see in their actions. Inspired by a narrative approach (see e.g. Carless \& Sparkes, 2008; see also Dowling, Fitzgerald, \& Flintoff, 2012) We have constructed brief narratives about three fictitious lessons. They are fictitious in the sense that they do not represent transcripts of particular lessons. Rather, we have assembled some of the transcripts from real lessons in order to construct, in a slightly speculative way, three PE lessons displaying what we interpret as significant patterns of social action in relation to what could be seen to be PE's educational contribution.

\section{Findings: a PE looks-like culture}

\section{The PE lesson looks-like-a-training session}

In the visited schools students have PE twice a week for between 40 and 60 minutes, or once a week for about 80 minutes. A standard lesson begins with a gathering, where the teacher takes notes about who is present and who is absent and then goes on to tell the students what will happen (what the students will do), often through naming a specific activity: 'Today we'll play football'. Only occasionally does the teacher articulate any specific purpose with the lesson. If they do articulate the purpose of the lesson some teachers use concepts that are mandatory and appear in the national curriculum, such as to 'plan, implement and evaluate sports and other physical activities' (SNAE, 2011a). However, many teachers rarely use mandatory concepts such as those included in the continuation of the aim stated in the previous sentence: 'based on different views of health, movement and lifestyle'. The theme of communicating the purpose of the lessons is further developed by Redelius et al. (2015).

Besides the fact that learning objectives are often obscure, limited time is devoted to a particular element in the schedule. With few exceptions, students seldom work with a particular content for more than one or two lessons. This might indicate a view of PE as a smorgasbord of activities, where students are supposed to gain knowledge and 
experience of activities that they can then devote their leisure time to (Annerstedt, 2008; Tinning \& Fitzclarence, 1992; see also Ward \& Quennerstedt, 2014).

The gathering is followed by a warm-up, which is either led by the teacher or by students. Occasionally, the students are asked to do the warm-up individually. The warm-up often consists of jogging and exercises, frequently performed to music (rather loud pop or rock music) and where large muscle-groups are used. Sometimes the warm-up takes the form of a game. The activity seems to serve the primary purpose of loosening the muscles and warming up the body in preparation for more physically vigorous activity. The loud music restricts verbal communication to occasional shouts.

Following the warm-up is the main activity, to which we will soon return. The lesson ends either with the main activity simply being interrupted and the students asked to go to the changing rooms, or, sometimes, with cooling down activities (including stretching) and a concluding gathering, where the teacher might ask what could be interpreted as rhetorical questions in order to make the students reflect on their level of activity during the lesson. The students might also be given the opportunity to say what they thought about the lesson, but not systematically based on any specific perspective (training, learning, recreation or else).

This lesson structure-warm-up, main activity, cooling down activities-is consistent with a training session. Thus, initially many lessons look as though they will take the form of training sessions, and to some extent, as will be shown below, they do thisalthough they also become something else. Verbal communication during the gathering and the warm-up mainly deals with what is going to happen in the subsequent main activity, or what the students are going to do. Hence, the introductory parts of the lesson open up for a training session, but the actions and interactions do not foreclose other possible directions. The lesson could be about quite a few things. Interestingly, judging by what is discussed at the concluding gathering, the lesson could have been about a number of things. We will now move on to the main activities.

\section{The PE lesson looks-like-physical training}

Included in the category looks-like-physical training are mainly activities that are designated 'circuit training', 'obstacle course', 'fitness/endurance' and 'fitness/ strength' in the term's schedule. Such activities occur in 12 of the 30 lessons. Tentatively, during these lessons one might expect the students to be involved in vigorous physical activity, where their actions and attention are directed towards developing strength, endurance and other physical properties at a reasonably fast pace with the aim of getting exhausted (Engström, 2008). Further, one might expect the teachers to cheer the students on in order to make them work harder and perhaps also offer feedback on the technical performance of the different exercises. Indeed, this is also what happens to some extent, but the keep-fit logic is frequently changed in ways that turn the lessons into something else. 
If explicitly stated by the teacher, the purpose of a looks-like-physical training session is rarely about actually developing physical properties. Rather, in the words of the teachers, it is about 'trying out different kinds of physical tests', 'exploring which muscles are trained', 'planning training' or 'planning, doing and evaluating a physical activity'. Arguably, these are educational purposes. Quite often, though, the purpose is not further developed by the teacher, or discussed among the students. Neither are there any clear links between any stated purpose and any particular pedagogy where, for instance, 'exploring which muscles are trained' is recontextualised into an educational situation. It rather appears as though the students are expected to explore which muscles are trained, and how, on their own.

In our analysis, the aim of trying out different exercises is consistent with what many students actually do during the lessons. Frequently, though, it seems unclear for what purpose the exercises are to be tried out. This leads to a situation where students move, for instance, through an obstacle course in the following way:

A class of 25 boys and girls from Year 9 move through an obstacle course which is designed as a W-shaped path on the gym floor. The different obstacles are vault boxes, beams or bars that are to be jumped or climbed over or crawled under. The course also contains a gymnastics-like movement, a sequence of somersaults on gym mats. The students move at quite a different pace. No particular task is articulated other than 'doing the obstacle course'. Some of the students actually get exhausted, while others move at a slow pace, perhaps 'trying out' the course. The teacher moves around in the gym, cheering some of the students on-'Well done! Come on, you can do more!'-while offering other students brief feedback about their technical performance, or trying to persuade other students to continue doing the exercise. Loud pop or rock music is playing in the background, which restricts verbal communication to occasional shouts. Students work in pairs, where one student is physically active while the other one rests. The exercise continues for about twenty minutes. As the lesson is coming to a close, the teacher asks the students to put the equipment away and then to gather in the middle of the gym floor. This gathering is very short. The teacher praises the students for their efforts and then tells them to go and shower.

Although the students do try out the exercises (some of them are obviously more familiar with doing an obstacle course than others), it is more difficult to see what is to be 'explored', or how the students are to 'plan and evaluate' training based on doing the obstacle course. In some of the upper secondary school classes the students were expected to plan training as a home assignment, but we could detect very few connections by teachers or students between the ('theoretical') home assignment and the ('practical') content of lessons consisting of keep-fit activities. In more straightforward language, the lesson became a kind of hybrid between a keep-fit session and a lesson in physical training (how to perform it and the principles behind it).

In other words, it looks like a keep-fit session, but the students' and the teacher's actions and attention are not primarily directed towards high intensity training. The interaction instead revolve to some extent around trying out and possibly exploring 
movements and to some extent also trying to make the lesson work, i.e. making it look as though everyone is active and doing their best and not feeling uncomfortable for not being active or good enough (cf. Ward \& Quennerstedt, 2014). The easygoing atmosphere is emphasised by means of a relaxed and sympathetic approach to the lesson. As there is no distinct objective to pursue (other than doing the exercises), there are few possibilities for teachers and students to actually assess whether the students are making any progress, either in their physical development or in their learning. In this hybrid form of keep-fit session and lesson in physical training the teacher becomes something in-between a fitness coach, i.e. an instructor and a motivator, and a teacher who facilitates learning by encouraging students to try out, explore the function or meaning of movement, or plan and evaluate the training.

\section{The PE lesson looks-like-sport}

The lessons that looks-like-sport include activities that in the schedule are designated 'floorball' (or 'unihoc'; a popular hockey-like game, played with plastic sticks), 'volleyball', 'table tennis', 'gymnastics' and the like. Such activities occur in 20 lessons. Tentatively, during these lessons one might expect the students to be involved in games and competitions, trying their best to win the game or beat the opponent, or attempting to improve their skills in different sports (Engström, 2008). Further, one might expect the teachers to referee matches or measure performances, or to be involved in skills instruction. This is also what happens, at least to some extent and among some students, but the sport and sport technique logics are sometimes changed in ways that turn the lessons into something else. Here, only in exceptional cases does the teacher articulate the objective of the lesson. Instead, the teacher almost exclusively talks about what is going to happen by naming the different sports or by using words like 'matches', 'games', or focusing on the rules of a particular sport. Thus, in comparison to the previous category, the educational dimension seems to be even more diffuse.

When viewing the video recordings, it is sometimes difficult to determine, judging by the actions and interactions of the teachers and students, what a sports lesson is actually about. Quite often, in particular when playing games, the activities mainly seem to have recreational ends. This leads to a situation in which students play sport or do technical drills, but where quite a few of them either display hesitation or indifference, albeit adopting a benevolent attitude (there is actually quite a lot of laughing and many happy faces) before the activities:

After the gathering and warm-up with an upper secondary class of some 30 students, both boys and girls attending a technical education, the teacher organises the class into pairs with the task of practising floorball passes while moving around the gym. The class is quite heterogeneous when it comes to their previous experiences and capabilities, which is indicated by some students using the stick with great hesitation and standing more or less on the same spot, while others move around at great speed and simultaneously keep an eye on their friend, always ready to receive or pass the ball. Loud music is emitted from the loudspeakers. 
The teacher mainly watches the students from the sideline during this activity. After a while the teacher introduces another drill. The students are now divided into two large groups facing either of the two goals on each side of the gym floor. Here, they are to practise the 'tensile shot', a common shot used in floorball. During this activity the teacher moves from one group to another, offering feedback about how to perform the shot, often in the manner of 'how to do it', i.e. mechanistically instructing how the movement should be performed from a technical perspective. The teacher mainly focuses on the less skilled students. Despite being engaged in some instruction, the teacher pays more attention to the more managerial aspects of the lesson, such as how to maintain order as 30 teenagers storm around, or how to make space for everyone, including the more inexperienced students. Loud music continues to stream from the loudspeakers, which makes verbal communication almost impossible. Halfway into the lesson the teacher turns the music off and divides the class into four teams. Two of the teams start playing against each other, while the other two watch. The atmosphere among the students is friendly. Attempts by one or two students to 'go for it' (i.e. to act competitively, to really try to win the game) are immediately met by discontent on the part of other students. In the main, the students oversee the rules themselves, but occasionally the teacher actively interrupts the game to deliver a verdict. While standing at the side, the teacher also discusses with one of the teams whether they believe this to be a suitable recreational game and what it takes for an individual to engage in floorball during their leisure time. After three matches, when each team has met all the other teams, the lesson is drawn to a close and the students are asked to leave the gym and go to the changing rooms.

This lesson includes elements of what Kirk (2010) calls PE-as-sport-techniques, although without any persistent attempts by the teacher to systematically develop the students' skills. Sports lessons are typically sequenced as training sessions: (1) technical drills, individually and in pairs (either as a cooperative event or as a minor competition), (2) small team games, e.g. teams of 2-4 players and (3) 'the real game' or 'the real sport' (often performed using pedagogical rules). Nevertheless, the activities during these lessons are frequently also changed by actions that express the message: 'this is actually not about improving your skills', 'this is actually not a real game'. This message is manifested through the essentially non-competitive atmosphere in the gym and the cautious and playful way in which the drills and games/ competitions are performed, which makes the activity look mainly recreational. Here, the teacher becomes something in-between a sports coach, an instructor and a recreational physical activity manager.

In sum, compared to doing sport-for-real, the studied teachers and students seem, with few exceptions, to agree that the important thing is to 'try' different sports, or to play playfully or cooperatively rather than to improve skills or win the game.

\section{The PE lesson looks-like-dancing}

Some of the observed lessons include dancing. Crudely put, two kinds of dancingestablished dances like ballroom dancing and folk dancing-are in focus in three lessons and in another three lessons the focus is on an exercise in which the students 
are expected to perform a music analysis (intro, verse, chorus, interlude, etc.) and subsequently create a dance choreography to the music in question. The latter kind of dancing is included in the looks-like-dancing category. The lessons on established dances more or less follow the pattern of looks-like-sport, and in particular the sporttechnique logic. Tentatively, during the looks-like-dancing lessons one might expect the students to be involved in composing movement choreographies with expressive movements based on the music analysis (Engström, 2008), and to some extent this is also what happens. Further, one might expect the teachers to teach the students how to do a music analysis and how to compose choreographies. This is also, to some extent, what happens.

In the activities that looks-like-dancing, some of the patterns that have been discussed above change, but not the sparsely articulated objective with the lesson. The objective, when articulated, is framed in rather vague ways, such as: for everyone to 'contribute to the group work', to 'develop the ability to dance', to 'develop leadership' or to 'cooperate'. However, in contrast to other lessons in which a minimum of student preparation is required, here the students-or at least one student in each group-are expected to have performed a music analysis as homework prior to the lesson. The lessons do not include a warm-up. After the gathering the students immediately form groups, which are either self-selected or organised by the teacher, and start deliberating about how to compose the choreography:

One group, consisting of six upper secondary school students, four girls and two boys, is in a classroom near the gym. The group is gathered around a piece of paper on which one of the students has written the music analysis. Another student is managing a musical device on a smart phone. The group listens to the intro and the first verse of a song. One of the students says: 'First, we can line up like this [organises the rest of the group into a straight line], and then we can do this with our arms'. 'Sure', says another student, 'but perhaps we can do this' [shows different ways of moving the arms, like a waving semaphore]. Some of the students cheer: 'Yes, that's great!' They all line up and try to perform the moves to the first beats of the song. Two of the students are very active in suggesting different moves, and another two make occasional suggestions. A fifth student tries, rather halfheartedly, to suggest one or two moves, but is mostly ignored by the other students. The sixth student is silent for the most part, but willingly participates in performing the choreography. After a while the teacher enters the room. At first the teacher merely watches and listens, but later, as the students run out of ideas, gets involved in the deliberations: 'What could you do next? Listen to the music ... It sounds a little bit like a staccato, don't you think?' 'Yes', one of the active students responds, 'we can do this' [tapping the left foot on the floor while standing on the right foot]. By the end of the lesson the group has composed a two-minute choreography that they intend to practise in the next lesson and then perform it in front of their classmates.

Unlike many other lessons, and unlike the overall result of the national evaluation of Swedish PE (Quennerstedt et al., 2008), these lessons include discussion and negotiation, partly because the music is used for a more specific purpose. 
However, less attention is paid to the actual kinds of movements, and the quality of the movements, and the students are more or less free to be inspired by different music video genres or movements that are commonly used in aerobics classes. In this way, the resulting choreographies are quite different in style, and, certainly from a dance perspective, one could ask whether the students actually manage to capture the rhythm and character of the music in their choreographies or express particular aesthetic values.

Here, the teacher is not so much an instructor or a coach, but more of a supervisor, facilitator and critical friend. Although the teachers teach the students how to perform a music analysis, they give very little instruction about how to compose movement choreographies or how movements could express aesthetic values. The teachers seem to prefer to hand over the assignment to the students and then 'wait and see' what they come up with. Based on what the students come up with, the teachers assume the role of facilitator and critical friend. To some extent the teachers use productive teaching approaches, particularly problem-solving (Kirk, Nauright, Hanrahan, Macdonald, \& Jobling, 1996). Contrary to most other lessons, the students are introduced to a comparatively distinct problem and are able to deliberate on this problem to find solutions that are not predetermined. Further, contrary to other lessons, the teacher often stays in the background and gives the students an opportunity to deliberate on and test out the different movements. There is no clear 'right or wrong' way, as is the case when practising different sporting techniques. The phrase 'this is how to do it' is not nearly as common as during the looks-like-physical training and looks-like-sport lessons. Rather, the main thing seems - still — to be that the students 'try' or 'make an effort', and, importantly, that each student contributes cooperatively to the assignment.

Although the dance logic is changed, we believe that the looks-like-dancing lessons point towards a pedagogy where the educational contribution is somewhat clearer in comparison to the looks-like-physical training and the looks-like-sport lessons; one in which students are to a greater extent cooperatively involved in the learning process and where the learning objectives are more clearly defined and negotiated by teachers and students alike.

\section{Discussion and conclusion}

In this article the aim has been to explore the ways in which practice unfolds (the logic of practice; see Engström, 2008, see also Bourdieu, 1990) in movement cultures that are included in Swedish PE, and how students and teachers, through their actions, negotiate what a PE lesson is about. Our analysis indicates that teachers and students are to some extent involved in pursuing a number of conventional sport logics, i.e. they try to develop the students' physical status and their sports and dancing skills, but not only that. From Ward and Quennerstedt (2014) we borrowed the concept of a 'looks-like' culture of PE in order to articulate what appears to be happening in the gym during the lessons we observed. In the main, students act in ways that make developing their physical status and their sports and dancing skills 
look like side issues. To some extent, the easygoing practice looks more like recreation, although having said this, the teachers and students are also involved in educational issues related to keep-fit, sport and dance activities. However, our conclusion is similar to Kirk's (2010), which is that a lot of exercises are decontextualised and that little time is devoted to a particular content. In fact, it is not always clear what the content is about, which might, in turn, explain the overuse of direct teaching (in order to keep the students busy) and inappropriate feedback or accountability (since the logic of practice of the lessons conveys many different ends; cf. Crum, 1993, p. 344).

How, then, is it possible to discuss the relationship between movement culture and the educational contribution of PE? On the one hand, the practice of PE may well continue in its present form. From the point of view of the teachers and the students there does not seem to be any impending need for change. Few Swedish studies, if any, report teachers or students advocating a need for change. Still, if more teachers and students were to watch PE lessons 'from the sidelines', as we did, and try to make sense of what PE is about, and in particular what its educational contribution is, then we believe that teachers and students would ask more or less the same questions as we have done. Perhaps this is also why Kirk (2010) calls for a radical reform of PE? But what does our study have to offer in terms of suggestions for reform? Answering such a question also needs to include interpretations about why the situation is as it is.

The looks-like culture of PE might, at least in part, be related to the subject's motley background. A lot of different aims and indeed dreams have been linked to PE (Bailey et al., 2009, for the Swedish context, see Quennerstedt, 2006). Thus, there are many parallel ways of making sense of the subject. Further, PE teachers, who are predominantly cultivated within medical and sport discourses, find the leitmotifs 'knowledge and learning' difficult to make sense of, because they mainly refer to a discourse known to policy-makers, researchers (such as ourselves) and teacher educators (Larsson, 2009). The mandated educational discourse, which is currently dominated by constructivist ideas that are in turn linked to constructivist pedagogies (Riis, 2000, pp. 25-28) do not appear to be entirely compatible with the somewhat mechanical and behaviouristic medical and sport discourses. For instance, the planning, application and evaluation of different types of activities involving physical movement based on different views of health, movement and lifestyle, as stated in the national curriculum, may be obscure due to PE teachers' limited knowledge about the different views of health, movement and lifestyle that are available. However, previous Swedish studies indicate that PE teachers are susceptible to change because they view $\mathrm{PE}$ as 'something else' in relation to sport and keep-fit activities outside school (Annerstedt, 1991; Lundvall \& Meckbach, 2004). Could it be that the imposed objectives of the subject, which some teachers do not even refer to when talking to their students, are diffuse and therefore of little help? Given many PE teachers' knowledge base, perhaps these objectives do not make sense when teachers make pedagogical considerations. In that case, there is a need to develop the language of 'knowledge and learning' in ways that make sense to PE teachers. 
Arguably, such a strategy would have to go hand in hand with the development of teaching strategies that help students to make educational sense of the activities that constitute the PE content. Hence, the problem is not only about stating intelligible objectives for PE, but also using pedagogies that, based on the language of knowledge and learning, have the power to frame the activities-sports, keep-fit activities and dancing - in ways that make sense to the students as education, rather than training. As stated above, we believe that the looks-like-dancing lessons have a lot to offer in this endeavour. Developing such teaching strategies would, we believe, have the potential to make PE a planned introduction into movement culture.

\section{References}

Annerstedt, C. (1991). Idrottslärarna och idrottsämnet [Physical education teachers and the subject of physical education] ( $\mathrm{PhD}$ diss). Gothenburg: University of Gothenburg.

Annerstedt, C. (2008). Physical education in Scandinavia with a focus on Sweden: A comparative perspective. Physical Education and Sport Pedagogy, 13, 303-318. doi:10.1080/1740898080 2353347

Bailey, R., Armour, K., Kirk, D., Jess, M., Pickup, I., Sandford, R., \& BERA Physical Education and Sport Pedagogy Special Interest Group. (2009). The educational benefits claimed for physical education and school sport: An academic review. Research Papers in Education, 24 (1), 1-27. doi:10.1080/02671520701809817

Barker, D., Quennerstedt, M., \& Annerstedt, C. (2013). Inter-student interactions and student learning in health and physical education: A post-Vygotskian analysis. Physical Education and Sport Pedagogy. Advance online publication. doi:10.1080/17408989.2013.868875

Barker, D., Quennerstedt, M., \& Annerstedt, C. (2015). Learning through group work in physical education: A symbolic interactionst approach. Sport, Education and Society. Advance online publication. doi:10.1080/13573322.2014.962493

Bourdieu, P. (1990). The logic of practice. Palo Alto, CA: Stanford University Press.

Carless, D., \& Sparkes, A. C. (2008). The physical activity experiences of men with serious mental illness: Three short stories. Psychology of Sport and Exercise, 9, 191-210. doi:10.1016/j. psychsport.2007.03.008

Crum, B. J. (1993). Conventional thought and practice in physical education: Problems of teaching and implications for change, Quest, 45, 339-356. doi:10.1080/00336297.1993.10484092

Dowling, F., Fitzgerald, H., \& Flintoff, A. (2012). Equity and difference in physical education, youth sport and health: $A$ narrative approach. London: Routledge.

Engström, L.-M. (2008). Who is physically active? Cultural capital and sports participation from adolescence to middle age - A 38-year follow-up study. Physical Education and Sport Pedagogy, 13, 319-343.

Kirk, D. (2010). Physical education futures. London: Routledge.

Kirk, D., Nauright, J., Hanrahan, D., Macdonald, D., \& Jobling, I. (1996). The sociocultural foundations of human movement. Melbourne: Macmillan.

Larsson, L. (2009). Idrott - och helst lite mer idrott [Sport - And preferably more sport] $(\mathrm{PhD}$ dissertation). Stockholm: Stockholms universitet.

Liljekvist, $\AA$ (2013). Rum för rörelse [Space for movement] ( $\mathrm{PhD}$ dissertation). Stockholm: Stockholms universitet.

Londos, M. (2010). Spelet på fältet [The play on the field] (PhD dissertation). Malmö: Malmö högskola. 
Lundvall, S., \& Meckbach, J. (2004). Fritt och omväxlande [Free and varied]. In H. Larsson \& K. Redelius (Eds.), Mellan nytta och nöje. Bilder av ämnet idrott och hälsa [Between use and pleasure. Images of physical education] (pp. 70-80). Stockholm: Idrottshögskolan.

Marshall, J., \& Hardman, K. (2000). The state and status of physical education in schools in international context. European Physical Education Review, 6, 203-229. doi:10.1177/135633 $6 \mathrm{X} 000063001$

McElroy, M. (2002). School physical education in crisis. In M. McElroy (Ed.), Resistance to exercise. A social analysis of inactivity (pp. 137-171). Champaign, IL: Human Kinetics.

Nyberg, G., \& Larsson, H. (2014). Exploring 'what' to learn in physical education. Physical Education and Sport Pedagogy, 19(2), 123-135. doi:10.1080/17408989.2012.726982

Quennerstedt, M. (2006). Att lära sig hälsa [Learning health] (PhD dissertation). Örebro: Örebro universitet.

Quennerstedt, M., Annerstedt, C., Barker, D., Karlefors, I., Larsson, H., Redelius, K., \& Öhman, M. (2014). What did they learn in school today? A method for exploring aspects of learning in physical education. European Physical Education Review, 20, 282-302. doi:10.1177/ 1356336 X 14524864

Quennerstedt, M., Öhman, M., \& Eriksson, C. (2008). Physical education in Sweden-A national evaluation. Education-line, 1-17. Retrieved from http://www.leeds.ac.uk/educol/documents/

Redelius, K., Quennerstedt, M., \& Öhman, M. (2015). Communicating aims and learning goals in physical education: part of a subject for learning? Sport, Education and Society. Advance online publication. doi:10.1080/13573322.2014.987745

Riis, U. (2000). Läroplanerna, konstruktivismen och det situerade lärandet [Curricula, Constructivism and the situated learning]. In U. Riis (Ed.), IT $i$ skolan mellan vision och praktik. En forskningsöversikt [ICT in school between vision and practice. A review of research] (pp. 2528). Stockholm: Skolverket.

Schenker, K. (2011). På spaning efter idrottsdidaktik [In search of a physical education didactics] ( $\mathrm{PhD}$ thesis). Malmö: Malmö högskola.

SNAE. (2011a). Curriculum for the compulsory school system, the pre-school class and the leisure time centre 2011. Stockholm: Author.

SNAE. (2011b). Curriculum for the upper secondary school 2011. Stockholm: Author.

SSI. (2010). Mycket idrott och lite hälsa [A lot of sport and little health]. Stockholm: Author.

SSI. (2012). Idrott och hälsa i grundskolan [Physical education and health in elementary school]. Stockholm: Author.

Stothart, B. (2005). Nine strikes and you're out: New Zealand physical education in crisis? The fournal of Physical Education New Zealand, 38, 95-102.

Tinning, R., \& Fitzclarence, L. (1992). Postmodern youth culture and the crisis in Australian secondary school physical education. Quest, 44, 287-303. doi:10.1080/00336297.1992.104 84056

Ward, G. (2014). Learning movement culture: Mapping the landscape between physical education and school sport. Sport, Education and Society, 19, 569-604. doi:10.1080/13573322.2012. 690342

Ward, G., \& Quennerstedt, M. (2014). Transactions in primary physical education in the UK: A smorgasbord of looks-like-sport. Physical Education and Sport Pedagogy. Advance online publication. doi:10.1080/17408989.2014.923991 